\title{
A LUCARNA DO INFINITO: BAUDELAIRE E A FOTOGRAFIA
}

\author{
Adalberto Müller \\ “...l'industrie photographique était le refuge de \\ tous les peintres manqués, trop mal \\ doués ou trop paresseux..."
}

Quando decidiu começar o Salon de $1859^{1}$ com uma difamação da fotografia, Baudelaire devia acreditar estar dando um passo importante para salvar a arte - e a poesia - de uma catástrofe: o seu controle pelo mau gosto burguês. No entanto, não imaginava que o tiro sairia pela culatra. À parte as leituras e as polêmicas que o ensaio suscitou ${ }^{2}$ - entre elas, a de Walter Benjamin ${ }^{3}$-, acredito que, mais do que condenar ou ratificar a opinião de Baudelaire (o que me parece improvável hoje) sobre a fotografia, interessa verificar como o autor das Flores do Mal se comportou diante da primeira etapa do surgimento daquilo que Vilém Flusser ${ }^{4}$ chama de imagens técnicas [Technobilder], e como seu comportamento pode servir de exemplo tanto ao intérprete da sua poesia quanto ao intérprete das relações entre tecnologia e cultura - mais especificamente, entre mídia e literatura. Ao primeiro, a leitura desse ensaio de Baudelaire, juntamente com os ensaios sobre a imaginação (do

\footnotetext{
${ }^{1}$ Trabalharei aqui com a edição crítica estabelecida por Wolfgand Drost e Ulrike Riechers e publicada em Baudelaire critique de l'art contemporain (Paris: Honoré Champion, 2006).

${ }^{2} \mathrm{Na}$ edição crítica do Salon de 1859, Drost e Riechers apresentam farta bibliografia sobre o assunto (: 221-263).

${ }^{3}$ Cf. BENJAMIN, W. Medienästhetische Schriften. Org. Detlev Schöttker. Frankfurt/Main: Suhrkamp, 2002. Em especial, o ensaio "Kleine Geschichte der Photographie", publicado no Brasil em: BENJAMIN, W. Obras escolhidas I. Magia e técnica. Arte e politica. São Paulo: Brasiliense, 1993. Outros textos sobre panorama e fotografia podem ser encontrados nas sessões Q (panorama) e Y (fotografia) dos Passagenwerk, em Gesammelte Schriften Band 5 Das Passagenwerk. Frankfurt/Main: Suhrkamp, 1990.

${ }^{4}$ Imagens técnicas, para Flusser, são aquelas geradas por/ em aparelhos (dispositivos técnicos) que pressupõem um conceito técnico-científico para sua produção, e não apenas a intervenção humana. Os aparelhos pressupõem "programas" desenvolvidos industrialmente por "programadores", dentro de um parque industrial.
} 
(Cf. SÜSSEKIND, Flora. Cinematógrafo das Letras. São Paulo: Companhia das Letras, 1987.)
(AVICE, J-C. e PICHOIS, C. Passion Baudelaire: I'ivresse des images. Paris: Les Editions Textuel, 2003: 119.) mesmo Salon), pode auxiliar na investigação sobre a importância do conceito de imagem/ imaginação na obra baudelairiana, sobretudo se se considera que as teses de Baudelaire sobre a imaginação imbricam-se com o ensaio sobre a fotografia; para o segundo - e aqui me posiciono -, a atitude de Baudelaire pode ser tomada como protótipo do comportamento do intelectual letrado diante de um universo midiático que estava surgindo, e que viria a acelerar a transformação da paisagem cultural, agora não mais dominada pela escrita, mas pelas imagens técnicas. Esse comportamento é, no caso de Baudelaire, de reação, e oriundo de uma incompreensão daquilo que realmente as imagens técnicas representam na transformação do modo de percepção e representação da realidade.

Mas convém ressaltar que a relação de Baudelaire com a fotografia é tão ambígua quanto sua relação com a burguesia - e aqui me parece oportuno discordar que a mera descrição" do gesto "antiburguês" do jovem Baudelaire seria suficiente para ancorá-lo definitivamente em um contexto social (de "luta de classes") de forma demasiado chapada, para usar um termo da fotografia. Baudelaire acusa a fotografia como acusou a frivolidade do burguês - frivolidade a que ele, com seu caráter aristocrático de dandy, não estava imune, como atesta seu interesse pela moda. Ao mesmo tempo, tinha entre seus amigos íntimos um fotógrafo, Nadar, que se posicionava pela defesa do caráter artístico da fotografia. Mais do que isso, Baudelaire deixou-se fotografar por Nadar e Carjat, e, como modelo, desenvolveu uma forma de "reflexão" que contradiz alguma das teses do ensaio sobre a fotografia:

Il suffit de penser à l'amitié de Baudelaire et de Nadar pour comprendre que ce procès fait à la photographie n'est qu'une partie d'une réflexion plus dialectique. Quand Baudelaire, en 1865, demandera un portrait à sa mère, il lui précisera ce qu'il attend de la photographie: "un portrait exact, mais ayant le flou du dessin".

Antes mesmo da querela da fotografia, convém retroceder a um ponto importante da história das mídias óticas e da mudança de percepção da realidade, particularmente no gosto que se vai formando de representação da cidade como imagem do mundo. A visão da cidade começa a se tornar uma prática com as primei-

\footnotetext{
${ }^{5}$ Refiro-me, é claro, ao trabalho do aluno de Adorno, Dolf Oehler. OEHLER, D. Pariser Bilder I (1830-1848): Antibourgeoise Ästhetik bei Baudelaire, Daumier und Heine. Frankfurt/Main: Suhrkamp, 1979. Cf. a edição brasileira: OEHLER, D. Quadros Parisenses. São Paulo: Companhia das Letras, 1997.
} 
ras mídias óticas. Já no século XVIII, a lanterna mágica e as "Guckkasten" (caixas óticas) espalham pela Europa essa curiosidade de ver cidades estrangeiras ou distantes. O panorama iria desenvolver ainda mais no público esse gosto pelas "vistas", que veremos mais tarde na fotografia e no primeiro cinema.

Quando Baudelaire acrescenta os “Tableaux parisiens” às Flores do $M a l,{ }^{6}$ a forma de representar a visibilidade das cidades através das "vistas" urbanas, característica das mídias óticas ainda em voga (caixas óticas, panorama), perpassa o seu modo de olhar para Paris. Claro, as suas referências mais evidentes são os quadros, e, mais do que isso, a forma de apresentação dos quadros nos museus e salóes, que permite ver a história da pintura de maneira simultânea (como, por exemplo, no poema "Les Phares"). Mas deve-se considerar que a própria pintura sofreu influência das práticas desenvolvidas nas mídias óticas*: primeiramente, com a utilização da camera obscura na construção da perspectiva e no detalhismo descritivo dos pintores holandeses; ${ }^{*}$ em segundo lugar, com a exigência de um grau de visibilidade cada vez mais abrangente depois dos primeiros panoramas.

A construção dos primeiros panoramas no início do século XIX coincide com as transformações advindas do processo de industrialização, e torna marcante, pela primeira vez na História, um problema que viria a ser a tônica da arte do século XX, a imbricação de tecnologia e arte (em termos baudelairianos, "indústria/ massas" e "imaginação/ artistas"). Dois fatos envolvendo o panorama marcam essa história: o primeiro panorama construído em Paris, em 1800, foi obra do americano Robert Fulton, que três anos depois viria a construir o primeiro barco a vapor, dando início a um ciclo de transformação nos transportes que teria grandes conseqüências sobre o modo de percepção e representação da realidade; no intuito de desenvolver o seu panorama, Louis Daguerre teria sido levado - a partir das experiências de Nicephore Nièpce - a desenvolver a primeira câmera fotográfica, o daguerreótipo. Como observa Heinz Buddemeier, " com sua invenção, Daguerre tem em vista um desenvolvimento das "Guckkasten", que, com seus jogos de luzes e sombras, já antecipam, na metade do século XVIII, a existência futura do sucessor do panorama, o diorama.

O panorama consistia numa sala circular fechada lateralmente, com uma entrada subterrânea que conduzia o visitante a uma

${ }^{6}$ Os “Tableaux parisiens” só entram na edição de 1861.
* (Cf. ALPERS, S. A arte de descrever: a arte holandesa no século XVII. São Paulo: EDUSP, 1999.)

* (Cf. ALPERS, S. A arte de descrever: a arte holandesa no século XVII. São Paulo: EDUSP, 1999.)

(BUDDEMEIER, H. Panorama. Diorama. Photographie. Entstehung und Wirkung neuer Medien im 19. Jahrhundert. München: W. Fink, 1970: 12.) 
-(BUDDEMEIER, H. Panorama. Diorama. Photographie. Entstehung und Wirkung neuer Medien im 19. Jahrhundert. München: W. Fink, 1970: 12.)

(BENJAMIN, W. "Daguerre oder die Panoramen". Em Medienästhetische Schriften. Op. cit.: 327.) plataforma situada no centro da sala. Nas paredes laterais, dispunham-se uma série de quadros, que, unidos, davam a impressão de ser uma única pintura circular, iluminada por uma abertura no teto. Ao andar pela plataforma, o visitante podia contemplar a representação de uma paisagem de grandes dimensōes, ou de uma cidade, nos mínimos detalhes. Um discurso apresentado pelo cidadão Dufourny na Assembléia, em Paris, em 15 de setembro de 1800, assim descreve o panorama de Fulton:

[le panorama] répresente la vue de cette imense citée (sic): le Spectateur (sic) est censé élevé (sic) sur la platteforme du Pavillon central du Palais des Thuileries; de ce point il embrasse un horizon imense, qui renferme non seulement la vue de Paris, mais encore une partie de la campagne environnante; il domine, il plane sur tous ces objets, il suit de l'oeil les rives de la Seine, se promène sous les arbres de (sic) thuileries (sic), ou circule dans les rues et places publiques; et sur quelque point que s'arrêtent ses regards, ils sont frappés de la vérieté avec laquelle sont rendus l'ensemble et les détails de cette imense perspective."

A descrição do cidadão Dufourny já contém a matriz de várias questões que viriam a eclodir na obra de Baudelaire, e que, muito mais tarde, seriam objeto de estudo da teoria da mídia: por um lado, já se percebe aí uma maneira de organizar o olhar em relação à cidade, em fazer dela objeto do olhar ("la vue de cette imense citée"); por outro lado, a experiência com o panorama oferece ao "espectador" uma nova maneira de se comportar em relação à imagem: um olhar que se fragmenta, na tentativa de apoderar-se do real (os verbos são, a esse respeito, significativos: "il embrasse"; "il domine"; "il suit de l'oeil"; "se promène"). ${ }^{7}$ Com a imagem circular do panorama, acrescenta Buddemeier, torna-se possível falar de uma fisiognomia da cidade, porque ele permite observar e vivenciar a cidade de modo bastante mais completo do que as imagens dos quadros isolados.

Walter Benjamin também veria no panorama uma nova forma de representar a cidade, e um novo momento na história do olhar. Mas o panorama também "anuncia uma reviravolta na relação entre arte e técnica", sendo também "a expressão de um novo modo de existência”. " Para Benjamin, a cidade vai se transformando, pouco a pouco, em modo de representar uma nação, e o panorama transforma a cidade em paisagem, onde mais tarde o flâneur procurará

\footnotetext{
${ }^{7} \mathrm{O}$ leitor das Flores encontrará no livro esses verbos relacionados ao olhar.
} 
os motivos de sua poesia. Ao mesmo tempo, o panorama provoca mudanças na percepção e na representação do real, que terão conseqüências no comportamento e na arte: "Em 1822 Daguerre inaugurou seu panorama em Paris. Desde então, essas caixas claras e brilhantes são os aquários do distante e do passado". 'Quando Daguerre passa a dedicar-se às experiências fotoquímicas de Nièpce, não imaginava que a fotografia iria possibilitar que a experiência perceptiva do panorama se tornasse portátil e ao alcance de todos. Pois poucos anos depois de sua invenção - que consistia na fusão da antiga camera obscura com a fotossensibilidade - ter sido patenteada, em 1851, foram produzidos 21 milhões de daguerreótipos. A fotografia, assim como o panorama, é um "dispositivo" que mobiliza a indústria e a arte, mas de uma maneira nova: por um lado, o gesto fotográfico se massifica, todos podem ser agora retratistas; por outro lado, a fotografia, cujo produto é passível de cópia, destitui o "caráter de autenticidade", a "aura" da obra de arte. Segundo Benjamin ${ }^{8}$, as técnicas de reprodução em massa não implicam apenas numa mudança "exterior" à arte (o fato de que todos possam ser "artistas" com um simples clique), mas uma modificação no próprio estatuto da arte na modernidade. A "queda da aura" é definitiva. Depois da fotografia, as pontes foram queimadas. $\mathrm{Ou}$ seja: já não podemos definir a arte por valores antigos (como o sublime e a autenticidade). É aí que o pensamento de Baudelaire, o poeta da Modernidade, entra em cena. E, mais do que isso, é nesse ponto que o ensaio de Baudelaire sobre a fotografia torna-se uma revelação. Tanto sobre as imagens técnicas quanto sobre o próprio poeta e as suas Flores do Mal.

A reação de Baudelaire à fotografia no Salon de 1859 ocorre justamente quando a fotografia busca um espaço no domínio da arte. Na exposição de 1857, no Palais de l'Industrie, graças ao esforço de Nadar, a fotografia busca pela primeira vez entrar no domínio da arte. Os organizadores da exposição, no entanto, recusam-se a admitir que a fotografia acompanhe o desenho, a pintura, a gravura e a litografia. Apesar disso, uma comissão formada por artistas e escritores (entre eles Delacroix e Gautier), manifesta-se favoravelmente à fotografia, o que irá despertar a reação de muitos estetas e, entre eles, Baudelaire.

\footnotetext{
${ }^{8}$ Refiro-me tanto a "Kleine Geschichte der Photographie" quanto a "Das Kunswerk im Zeitalter seiner Reproduzierbairkeit”, ambos em Medienästhetischen Schriften.
}

• (BENJAMIN, W. "Kaiserpanorama". Em Medienästhetische Schriften. Op. cit. 325$. 
(BAUDELAIRE, C. Salon de 1859. Em Baudelaire critique de l'art contemporain. Op. cit.: 10.)

- (Citado por BUDDEMEIER, H. Panorama. Diorama. Photographie. Entstehung und Wirkung neuer Medien im 19. Jahrhundert. Op. cit.: 244.)

-(BAUDELAIRE, C. Salon de 1859. Op. cit.: 11.)
$\mathrm{O}$ argumento de Baudelaire no Salon não se dirige unicamente à fotografia, mas a todas as formas de arte que se submetem ao "Verdadeiro", em detrimento do "Belo": "chez nous le peintre naturel, comme le poëte naturel, est presque un monstre. Le goût exclusif du Vrai (si noble quand il est limité a ses véritables applications) opprime ici et étouffe le goût du Beau" É verdade que o "público burguês", a quem Baudelaire irá se referir, admira na fotografia o seu caráter de transparência e fidelidade (algo a que o panorama já o educara). Contudo, já no tempo de Baudelaire, era comum pensar-se no caráter artificial da fotografia em relação à realidade, a começar pela ausência de cores. Sobre o retrato, em 1841, RodolfTöpffer ressaltava o fato de que a cada instante um rosto se transforma, e a fotografia só pode registrar um desses instantes: "en quelque instant que $M$. Daguerre vienne fixer là votre image, cette image de votre figure d'un instant ne sera que le quart, que le demi-quart, que le dixième, que le centième de vous même". *

É interessante observar que Baudelaire, para criticar a fotografia, sempre opta por extremos. Por exemplo, um de seus exemplos é o "tableau vivant" praticado pelos ingleses, forma de fotografia em que se representavam, nas fotos, fatos históricos, com atores. Para Baudelaire, tratava-se de uma "étrange abomination":

Quelque écrivain démocrate a du voir là le moyen, à bon marché, de répandre dans le peuple le goût de l'histoire et de la peinture, commetant ainsi un double sacrilège et insultant à la fois la divine peinture et l'art sublime du comédien. Peu de temps après, des miliers d'yeux avides se penchaient sur les trous du stéréoscope comme sur les lucarnes de l'infini.'

O estereoscópio era uma nova sensação entre as novas mídias óticas do século XIX e consistia numa espécie de binóculo que permitia criar o efeito de tridimensionalidade nas fotos. Claro que tal descoberta seria vista por Baudelaire com maus olhos, pois dava à fotografia algo que a pintura sempre buscara (através da perspectiva), e que Baudelaire rebaixa, sob a categoria de gosto vil, relegando-a à "idiotice do público". " Mais do que isso, ressalta o fato de que o estereoscópio seria usado predominantemente para mostrar obscenidades. A crítica de Baudelaire lembra a crítica dos primeiros anos da televisão, ou do computador, quando se diabolizavam essas mídias pelo fato de que só transmitissem imagens fúteis, obscenas ou violentas, que só idiotizariam o público. Baudelaire, como muitos pensadores críticos do século XX, fala em nome da Ar- 
te ("divine peinture") contra a massificação (e a mudança de percepção) trazida pelas novas mídias.

É necessário observar que, na "Kleine Geschichte" de Benjamin, Baudelaire entra pela porta dos fundos, e de maneira quase acidental. Isto é, Benjamin o coloca no meio dos dois parágrafos finais de seu ensaio, e, mais do que isso, contrapóe-no a um outro pensador, Antoine Wiertz, que apresenta uma visão oposta à sua sobre a fotografia. Mas é justamente nesse momento final, e com esse contraponto, que Benjamin põe em cena a pergunta: fotografia é arte? Antes mesmo, Benjamin já vinha embaralhando as cartas, ao dizer que a pergunta deveria pressupor o seu contrário (a arte, hoje, é fotografia?).* Trata-se de pensar a "Verfall des Kunstsinns", a queda do sentido da própria arte no mundo industrializado. Mundo que, para o bom marxista, coisifica as relações humanas ("also etwa die Fabrick"). Nesse sentido, para Benjamin, tanto a defesa apaixonada de Wiertz quanto o ataque veemente de Baudelaire parecem não responder à questão central do ensaio, que é a de saber se, num mundo em que a obra de arte perdeu a aura, ainda é possível outra forma de autenticidade. Benjamin vê na obra e na reflexão sobre a fotografia dos surrealistas uma saída, assim como assinala que a fotografia, no cinema russo, aponta para a possibilidade de uma nova etapa para se pensar o caráter criativo e o construtivo da fotografia."

O próprio Delacroix, ídolo de Baudelaire, embora mantivesse uma posição análoga à de Baudelaire - sem, é claro, a retórica arrasadora - anteviu uma possibilidade ainda mais promissora não apenas para a fotografia, mas para aquela imbricação entre a máquina e o homem, entre a indústria e a arte, que a fotografia representa de forma mais evidente. Referindo-se à utilização de técnicas de desenho a partir do decalque do objeto em gazes transparentes, ou através da daguerreotipia, Delacroix vê uma estranha fusão entre o artista e a máquina: "l'artiste, en un mot, devient une machine attelée à une autre machine" . Para Baudelaire, no entanto, a máquina (metáfora do progresso material, que ele condena), deveria limitar-se ao seu caráter de ser "la très humble servante" das ciências e das artes, "comme l'imprimerie ou la sténographie". Esse pensamento se completa com a idéia de ódio (que lembra, agora sim, a luta de classes) entre a poesia e o progresso (a imaginação e a técnica): "La poésie et le progrès sont deux ambitieux qui se haïssent d'une haine instinctive, et, quand ils se rencontrent dans le même chemin, il faut que l'un de deux serve l'autre".
• (BENJAMIN, W. Medienästhetische Schriften. Op. cit.: 312.)

$*(: 314)$

$*(: 314$.

*(Citado por BUDDEMEIER, H. Panorama. Diorama. Photographie. Entstehung und Wirkung neuer Medien im 19. Jahrhundert. Op. cit.: 251.)

* (BAUDELAIRE, C. Salon de 1859. Op. cit.: 13.)

$*(: 12$. 
(PICHOIS, C. e AVICE, JP. Dictionnaire Baudelaire. Tusson (Charente): Editions du Lérot, 2002: 329.)
Por essas e outras razões, percebe-se que o mesmo poeta que vê na dialética do "transitório" e do "eterno" o caráter positivo da modernidade recusa-se a admitir qualquer possibilidade de uma "maquinação" entre a poesia e a técnica. É claro que sua posição se enquadra, em primeiro lugar, na tentativa de resgatar o papel da imaginação ("a rainha das faculdades") contra o realismo (sobretudo de Courbet). Também fala aí o esteta da fantasia e da supra-realidade, que afirma que "a natureza é feia" e que prefere "les monstres de [sa] fantaisie à la trivialité positive”. * Estranhamente, no entanto, a fotografia cumpre, para Baudelaire, um papel que, ao fim e ao cabo, muito recorda o do poeta das Fleurs:

Qu'elle [la photographie] sauve de l'oubli les ruines pendantes, les livres, les estampes et les manuscrits que le temps dévore, les choses précieuses dont la forme va disparaitre et qui demandent une place dans les archives de notre mémoire, elle sera remerciée et applaudie.

No entanto, afirma Baudelaire, que a "empregada humilde" não se atreva a entrar no recinto do "impalpável e do imaginário", pois aí é o reino da Arte, da Poesia, das coisas divinas, que não se misturam com o comércio das coisas do mundo. Não estamos aqui, por acaso, diante da mesma tensão dialética que perpassa As Flores do Mal, e que se pode ler num poema como "Élévation"?

Mais ambígua é, enfim, a posição de Baudelaire modelo. Ao deixar-se fotografar pelo amigo Nadar, devia saber que estava tentando escapar do "oubli" das coisas "précieuses qui demandent une place dans les archives de notre mémoire”. As sucessivas fotos que tirou demonstram também que Baudelaire vai se tornando um modelo inquieto e desobediente ao registro da nitidez realista, buscando criar ele mesmo, como modelo, aquele "flou" que ele solicitava no retrato de sua mãe. Sabe-se que Nadar, burguês e artista, que teria sido também amante de Jeanne Duval, submeteu Baudelaire a longas sessões de fotografia:

Si Nadar a pu soumettre Baudelaire, dont il savait qu'il condamna violemment l'industrie photographique, à de longues scéances de pose en au moins trois occasions, c'est, sans doute qu'il avait su lui prouver que loin de livrer le public à l'admiration de "sa triviale image", la photographie pouvait saisir à travers son objectif cet impalpable, cette "âme", que Baudelaire afirmait inaccessible à cette "industrie". 
Resta saber, enfim, se o arquivo de ruínas a que se refere Baudelaire, esse acúmulo de imagens técnicas, não substituiu definitivamente o mundo da imaginação e da fantasia, e se somente nesse arquivo gigantesco, nessa "lucarna do infinito" é possível encontrar algum traço de beleza e poesia. Pois, como diria Drummond, Baudelaire agora é só um retrato na parede: "mas como dói". 


\section{Adalberto Müller}

Professor Adjunto II do Departamento de Teoria Literária (TEL) da Universidade de Brasília. Traduziu $O$ partido das coisas (Iluminuras, 2000) e $A$ mimosa (Editora UnB, 2003) de Francis Ponge.

Palavras-chave: Baudelaire; Fotografia; Imagem; Poeta; Mídia
Key words: Baudelaire; Photography; Image; Poetry; Media

Mots-clés: Baudelaire; Photographie; Image; Poète; Media
Recebido em 02/05/2007

\section{Resumo}

Em seu comentário agressivo à fotografia na abertura do Salon de 1859, Baudelaire parece pintar um auto-retrato do esteta antiburguês. No entanto, a posição de Baudelaire relativamente à fotografia é ambígua e deve ser entendida dentro do contexto paradoxal de seu amor à modernidade e ódio ao progresso. Através da leitura desse texto, pretendemos demonstrar o importante papel que ele desempenha na teoria baudelairiana da imaginação e mostrar como ele pode revelar uma certa cegueira dos poetas e literatos relativamente às novas tecnologias de (re)produção da imagem.

\section{Abstract}

In his aggressive commentary on photography at the opening at Salon de 1859, Baudelaire seems to depict a self-portait of an anti-bourgeois aesthete. Nevertheless, Baudelaire's position regarding photography is ambiguous, and must be understood in the context of his paradoxical admiration for modernity and hatred for progress. By reading this commentary, I intend to demonstrate the important role it plays in Baudelaire's theory of the imagination, and to show how it can reveal a certain blindness of poets and literary scholars vis-à-vis new technologies of image (re)production.

\section{Résumé}

Dans son commentaire agressif de la photographie lors de l'ouverture du Salon de 1859, Baudelaire semble peindre un auto-portrait de l'esthète anti-bourgeois. Pour autant, la position de Baudelaire relative à la photographie est ambiguë et doit être comprise dans le contexte paradoxal de son amour de la modernité et de sa haine du progrès. À travers la lecture de ce texte, nous avons l'intention de démontrer le rôle important qu'il joue dans la théorie baudelairienne de l'imagination et de montrer comment il peut révéler un certain aveuglement des poètes et littérateurs par rapport aux nouvelles technologies de reproduction de l'image. 